\title{
Measuring Reflective Functioning in Adolescents: Relations to Personality Disorders and Psychological Difficulties
}

Josée Duval $^{1}$, Karin Ensink ${ }^{1 *}$, Lina Normandin ${ }^{1}$, Carla Sharp $^{2} \&$ Peter Fonagy $^{3}$

${ }^{1}$ Université Laval, École de psychologie, Québec, Canada

${ }^{2}$ Department of psychology, University of Houston, Houston, USA

${ }^{3}$ University College London, Psychoanalysis Unit, Research Department of Clinical, Educational and Health Psychology, London, UK

Running head: Adolescent Reflective Functioning

*Address correspondence to this author: at Pavillon Félix-Antoine-Savard, FAS-1426, Université Laval, École de psychologie, 2325 rue des Bibliothèques, Québec (QC), Canada G1V 0A6

Phone: +1 (418) 656-2131 \#12493

Email: Karin.Ensink@psy.ulaval.ca 


\section{Measuring Reflective Functioning in Adolescents: Relations to Personality Disorders and Psychological Difficulties}

Background: Reflective Functioning (RF) is considered to play a central role in risk and resilience for psychological difficulties such as borderline personality disorder (BPD) and has become an important treatment target of transdiagnostic psychosocial interventions like Mentalization Based Therapy. However, a lack of measures to assess RF in adolescents has hampered research that can further elucidate the role of RF in different types of psychopathology.

Objective: The objective of the present study was to examine the validity of the Reflective Functioning Questionnaire for Youth (RFQ-Y), examine the factor structure of the french RFQY, the relationship between RFQ-Y and social cognition, psychological difficulties, BPD and narcissistic personality disorders.

Method: A total of 533 adolescents and young adults (age $12-21$ ) from the community completed the RFQ-Y, the Child Behaviour Checklist, the Borderline Personality Features Scale and the Pathological Narcissism Inventory. A subsample of 150 participants completed the Movie for the Assessment of Social Cognition (MASC).

Results: Three factors were identified. Uncertainty/confusion was strongly positively correlated with psychological difficulties, especially symptoms of borderline personality disorder. Interest/curiosity was negatively correlated with and psychopathology and Excessive Certainty correlated significantly with grandiose narcissism. RFQ-Y factors correlated more strongly with psychopathology than the MASC scales. 
Conclusion: This study demonstrates the validity of self-report measures like the RFQ-Y and its utility for identifying problematic styles of mentalizing associated with increased risk of psychopathology in general, as well as difficulties like narcissism in particular.

Keywords: Reflective functioning, mentalization, adolescent, borderline, narcissism, internalizing, externalizing 


\section{INTRODUCTION}

Mentalizing, falling under the general rubric of social cognition, is considered to involve abilities that have important implications for interpersonal functioning and mental health. As a result, mentalizing has become a central construct in models of mental disorders and their treatment. Transdiagnostic psychosocial interventions, like Mentalization Based Therapy (MBT) (Bateman \& Fonagy, 2010), have been elaborated and tested specifically to target problems of mentalizing. It has become apparent that a number of aspects of mentalizing may have implications for psychopathology (Fonagy \& Luyten, 2009), but there is a lack of available instruments to identify the relative strengths of dimensions of mentalizing.

A self-report measure of mentalizing, the Reflective Functioning Questionnaire for Youth (RFQ-Y), has recently been developed based on an adult instrument (Fonagy \& Ghanai, unpublished manuscript), and some initial validation data is already available (Ha, Sharp, Ensink, Cirino \& Fonagy, 2013). The latent structure of this instrument has not yet been explored, yet we anticipate on theoretical and empirical basis that underlying dimensions of mentalizing are differentially implicated in clinical problems that imply mentalization difficulties (Fonagy \& Luyten, 2016; Luyten, Mayes, Nijssens \& Fonagy, 2017). For example, a very brief version of the RFQ has been validated for use as a screening instrument with adults (Fonagy et al., 2016), and adolescents (Badoud et al., 2015). However, the longer version of the RFQ may be useful to detect a greater variety of mentalizing difficulties and differentiate and identify which specific types or combination of difficulties are associated with specific psychological problems. The aim of this study was to further examine the psychometric properties of a French translation of the Reflective Functioning Questionnaire for Youths (RFQ-Y; Ha et al., 2013), and to identify types of mentalizing difficulties in a community sample of adolescents and young 
adults.

\section{Mentalizing and adolescent psychological problems}

Mentalizing as conceptualized by Fonagy, Gergely, Jurist and Target (2002) refers to the processes involved in imagining why another behaves the way they do, while also being cognisant of our own emotional reactions, their connection to our beliefs and the impact of our mental states on others. Mentalizing renders the behaviour of others understandable and predictable, and also underlies self-awareness (Allen, Fonagy \& Bateman, 2008). This is considered especially important in the context of close attachment relationships because when the reactions of others are interpreted in terms of mental states, this enhances sensitivity and influences the manner in which we react to others (Fonagy \& Target, 1997). Fonagy et al. (2002) propose a developmental model whereby awareness of mental states emerges in the context of early attachment relationships, in which children learn to identify and mentally represent their own affects through observing the parent's interest in their subjective experience. Furthermore, the parents' capacity to imagine the subjective experience of their infant/young child is considered to facilitate the emergence of self-regulation, as well as representation of and communication about affects (Fonagy, 2004). Consistent with this, parental reflective functioning has been shown to be associated with infant attachment, (Ensink et al., 2016; Grienenberger, Kelly \& Slade, 2005; Stacks et al., 2014) as well as child and adolescent reflective functioning (Benbessat \& Priel, 2012; Ensink et al., 2015).

Mentalizing and socio-cognitive capacities that have developed during the course of childhood are considered to be particularly important during adolescence and to be central for the successful psychosocial transition to adulthood (Braehler \& Schwannauer, 2012). Mentalizing difficulties likely create vulnerability to mental health problems in youths. In line with this, there 
is evidence that difficulties in mentalizing are associated with a variety of psychological problems in both school aged children (Ensink, Bégin, Normandin \& Fonagy, 2016) and adolescents (Ha et al., 2013; Taubner, White, Zimmerman, Fonagy \& Nolte, 2013).

\section{Mentalizing and Social Cognition}

Mentalization, as conceptualized by Fonagy, has been operationalized as Reflective Functioning (RF) for research purposes. A number of different measures are currently used to assess this, including the Adult Reflective Functioning Scale (ARFS; Fonagy, Steele, Steele, \& Target, 1998), the Addendum for Coding Reflective Functioning for use with the Parental Development Interview (PRFS; Slade, Bernbach, Grienenberger, Levy \& Locker, 2005) and the Child and Adolescent Reflective Functioning Scale (CARFS; Ensink, Target, Oandasan \& Duval, 2016). The ARFS, PRFS and the CARFS are criterion measures of RF applied to interview transcripts, but they are time consuming to administer, transcribe and code, and require resources that are unlikely to be available in clinical settings. A further disadvantage is that these measures generally yield a global score of participants' RF ranging from -1 to 9 , and information regarding difficulties in specific dimensions of mentalizing that may have important clinical implications and be of interest for clinicians, are not presently formally captured. As a result, there considerable interest in developing reliable clinically meaningful self-report measures of mentalization that ideally assess different dimensions of mentalizing difficulties.

To address the need for a self-report measure of mentalizing, the Reflective Functioning Questionnaire (RFQ; Fonagy \& Ghanai, unpublished manuscript) was developed for adults. A validation study of a brief 8 item version of RFQ was recently published which shows a twofactor structure (certainty and uncertainty regarding mental states of self and others) that 
correlated with measures of empathy, mindfulness and perspective-taking as well as with indices of maladaptive personality functioning (Fonagy et al., 2016). In addition, we have, in a previous study, presented the psychometric properties of an English youth version (RFQ-Y; Ha et al., 2013). RF on this measure was found to be positively associated with the CARFS global score as well as an experimental video task of social cognition. It was also, as predicted, negatively associated with borderline personality traits in an inpatient sample of adolescents.

\section{Mentalization, psychological difficulties and personality disorders}

RF has been shown to be inversely correlated with depressive symptoms and externalizing difficulties in children (Ensink et al., 2016). There is also evidence that major depressive disorder in adults is associated with lower RF (Fischer-Kern et al., 2013). Deficits in mentalization (measured as RF) have also been shown to be present in adults with borderline personality disorder (Bateman \& Fonagy, 2004) and eating disorders (Skarderud, 2007a, 2007b). In adolescents, RF has been shown to moderate the relationships between psychopathic traits and aggressive behaviors (Taubner et al., 2013). Mentalization, as measured with the brief 8 item RFQ or with the RFQ-Y, has also been shown to be negatively correlated with borderline traits, as well as internalizing and externalizing difficulties in adolescents (Badoud et al., 2015; Ha et al., 2013). In contrast to the numerous studies on social cognition and BPD, studies of social cognition and pathological narcissism remain relatively rare. However, from a theoretical perspective, uncertainty, but also over-certainty about mental states, where one's own perspective is assumed to represent reality while disregarding the fact that others are likely to be alternative perspectives, have been postulated to be associated with vulnerable and grandiose narcissism (Ensink et al., in press). However, this remains to be tested empirically. 


\section{The present study}

The RFQ is a promising measure, but there is room for exploring different ways of using the measure to assess key domains of mentalizing. For example, we previously examined the internal consistency of the RFQ-Y, because we were interested in whether the overall score could be used as a reliable indicator of RF in youth (Ha et al., 2013). While we found internal consistency to be within the acceptable range, it was at the lower end, leading us to suspect that it may be possible to identify different factors within the RFQ-Y. This expectation is consistent with previous studies where different factors were identified in the short version of the adult RFQ (Fonagy et al., 2016), as well as in the parental RFQ (Luyten et al., 2017). Furthermore, we wanted to re-examine the scoring of scale A of the RFQ-Y where both low and high scores are considered indicative of poor mentalizing and scores in the middle are considered indicative of good mentalizing, given that performance on this scale has not been found to be associated with psychopathology (Fonagy et al., 2016).

The aim of the present study was to further examine the psychometric properties of the RFQ-Y in a community sample of French-speaking adolescents. More specifically, the objectives were first, to examine the factor structure of the RFQ-Y, and second, its construct validity via its association with indicators of adolescent psychopathology, and its relationship with another measure of mentalization from a social cognition perspective, the Movie for the Assessment of Social Cognition (MASC; Dziobek et al., 2006). A third objective was to examine which dimensions of mentalizing difficulties identified by the RFQ and the MASC have the strongest relationship with specific clinical problems. 
Although we conducted exploratory factor analysis and did not have definite hypotheses regarding possible factors, based on previous findings with the RFQ, we tentatively hypothesized that we would find both a certainty and an uncertainty factor (Fonagy et al., 2016) and that we would find significant inverse correlations between certainty and uncertainty of the RFQ and dimensions of good mentalizing on the MASC and significant positive correlations between uncertainty on the RFQ and hypermentalizing on the MASC. Finally, given that few studies on mentalizing used both the RFQ and the MASC, and examined the respective contributions of both measures regarding psychopathology, we did not have specific hypotheses.

\section{METHOD}

\section{Participants}

The sample consisted of a total of 533 adolescents and young adults age 12 to 21 years old $(\mathrm{M}=17.94, \mathrm{SD}=3.91) ; 354(66.4 \%)$ were girls. Approximately $92.5 \%$ of the adolescents identified as Caucasian, $1.7 \%$ as Afro-American, $2.9 \%$ as Asian and 2.9\% as other. Participants were recruited from seven high schools in the Quebec region and from Laval University. Descriptive statistics for participants and measures are summarized in Table 1. A sub-sample of 150 participants also completed the Movie for the Assessment of Social Cognition (MASC; Dziobek et al., 2006).

Adolescents 14 years and older consented to participate in the study by completing a consent form. The consent provided by the adolescents was in accordance with Article 21 of the Civil Code of Québec which specifies that from age 14 adolescents can decide to consent to certain activities such as participating in research. For 12- and 13-year-old, parental consent was required prior to their participation in the study. Once parental consent was received, a link was 
forwarded by e-mail to the adolescents so they could complete the online questionnaires. The study was approved by the Ethics Committee for Research with Human Subjects of Laval University.

\section{Measures}

Reflective functioning (RF). The Reflective Function Questionnaire for Youth (RFQ-Y; Sharp et al., 2009) is a 46-item self-report questionnaire used to assess adolescent RF. Item responses are indicated along a six-point Likert scale ranging from 'strongly disagree' to 'strongly agree'. The instrument was originally conceptualized as having two 23 -item subscales (A and B) with the usual Likert coding used for scale B, but median scoring method for scale A where median scores indicated higher RF. Because of the limitations previously found using the median scoring method for scale A (there was an absence of correlations with pathology and other measures of RF and mentalizing), we re-examined the scoring system and used the standard Likert continuous scoring method for scale A as for scale B. All 46 items of the questionnaire (including scale A and B) were thus scored using the same Likert scale.

The English questionnaire was translated into French by our team and back-translated from French to English by two students not involved in the study. The wording of each item was carefully revised by first comparing the back-translation with the original version to identify potential areas of difficulty/divergence. In cases where the back-translation diverged from the original English version, the bilingual team examined and discussed the source of divergence until consensus was reached regarding potential solutions. This version was then again backtranslated until the team was satisfied that the translated version accurately represented the meaning of the items in the original English questionnaire. Special attention was paid to the 
selection of simple and precise French words to facilitate adolescent readers' comprehension of all questionnaire items.

Mentalization. The Movie for the Assessment of Social Cognition (MASC; Dziobek et al., 2006) was used to measure the construct validity of the RFQ-Y. The MASC is a computerized video task developed to assess mentalization capacities and consists of a 15 minute video that depicts a dinner party where themes of friendship and romantic interest are emphasized. In each video clip, the character is confronted with a situation which elicits a variety of emotions and mental states like anger, affection, jealousy, fear, shyness, disgust and gratitude. Whilst some of the characters are friends, some are meeting for the first time. These different aspects of the movie permit the assessment of the participant's ability to infer the mental states of others in various types of social interactions. The video pauses 45 times to ask the participant a question about the mental states of the characters in the movie. Respondents are then asked to choose between four possible response options: (1) a hypermentalizing response, (2) an undermentalizing response, (3) a no mentalizing response, and (4) an accurate mentalizing response. Each type of response corresponds to a scale on the measure and a score can be calculated for each scale. The MASC is a reliable measure which has detected subtle mentalization differences among adult patients with multiple sclerosis (Pöttgen, Dziobek, Reh, Heesen, \& Gold, 2013), bipolar disorder (Montag et al., 2010), major depression (Wolkenstein, Schonenberg, Schirm \& Hautzinger, 2011), schizophrenia (Montag et al., 2011), social anxiety (Buhlmann, Wacker, \& Dziobek, 2015) and borderline personality disorder (Preissler, Dziobek, Ritter, Heekeren \& Roepke, 2010). The MASC has been demonstrated to be a reliable instrument to assess social-cognition in adolescents (Ha et al., 2013). The current study used a French 
version of the MASC which was translated by a team from Ste. Justine's Hospital in Montreal who are also validating the instrument (Bossé-Chartier, 2013).

Internalizing and externalizing behaviours. The French version of the Youth SelfReport (YSR; Achenbach, 1991) is used to assess emotional and behavioural function in adolescents. The standardised self-report questionnaire contains 112 items divided into 8 subscales: withdrawal, somatic complaints, anxiety and depression, social problems, thought disturbances, attentional difficulties, aggressive behaviour and delinquent behaviour. The first three subscales are part of the internalizing behaviour scale, while the aggressive and delinquent behaviour subscales comprise the externalizing scale. Internalizing and externalizing scale scores as well as the overall score are calculated by summing individual item scores for the relevant subscales. In our sample, the internalizing and externalizing scales showed good internal consistency with Cronbach's alphas of .91 and .82 respectively.

Borderline traits. The Borderline Personality Features Scale for Children (BPFS-C; Crick, Murray-Close, \& Woods, 2005) is a self-report questionnaire consisting of 24 items related to borderline personality traits among children and adolescents age 9 and over. The BPFS-C was adapted from the borderline personality subscale of the Personality Assessment Inventory (PAI; Morey, 1991), a valid and reliable measure of personality pathology in adults. The BPFS-C contains four subscales akin to those found in the PAI: affective instability, identity problems, negative relationships and self-harm. Each subscale contains six items. Item responses are indicated along a 5-point Likert scale ranging from $(1)=$ not at all true to $(5)=$ always true Scores for four of the six items in each subscale are reversed and a total score is then calculated by summing the scores for each item. An elevated score is indicative of the presence of several borderline personality traits. The French version used here has been shown to have good internal 
consistency with a Cronbach alpha of .91 for the total score (Bégin, Ensink, Kotiuga, Leclerc, Thériault-Sereno, \& Normandin, submitted). In our study, we also had a good internal consistency with a Cronbach's alpha of .91.

Narcissism. This study used the French version of the Pathological Narcissism Inventory (PNI; Pincus et al., 2009) adapted for adolescents (Chrétien, Ensink, Descoteaux \& Normandin, submitted). The PNI-A is a 52-item self-report questionnaire which assesses pathological narcissism and specifically the presence of grandiose and vulnerable narcissism. It consists of seven scales: 1) contingent self-esteem, 2) exploitative, 3) self-sacrificing self-enhancement, 4) hiding the self, 5) grandiose fantasy, 6) devaluation, and 7) entitlement rage. Answers are indicated along a 6-point Likert scale ranging from $(0)=\mathrm{I}$ am really not like that to $(5)=\mathrm{I}$ am very much like that. Average scores are calculated for each scale. The grandiose narcissism score is calculated by summing and averaging the scores for the exploitative, self-sacrificing selfenhancement, and grandiose fantasy scales, while the vulnerable narcissism score is obtained by summing and averaging contingent self-esteem, hiding the self, devaluation, and entitlement rage scale scores. The French PNI-A has been shown to have a robust factor structure, good test-retest reliability, and good construct validity. In addition, the same two-factor structure representing grandiose and vulnerable narcissism demonstrated to be present for the adult PNI was replicated in the French PNI-A (Chrétien et al., submitted). For the current sample, the internal consistency for grandiose and vulnerable narcissism scales was good, with Cronbach's alphas of .87 and .92 .

\section{Procedure}

The study was presented to all students at schools who agreed to study participation and permission was obtained to use the mailing list of the university to invite potential participants. 
After giving their consent, students at schools were invited, depending on the agreements with school's principals, to log onto a secure website which contained the RFQ-Y, the BPFS-C, the PNI-A, the YSR and the MASC, or to complete paper-and-pencil versions of the questionnaires. The secure website included a description of the study, a consent page, and all questionnaires in a user-friendly online format. Each questionnaire was displayed on a unique webpage and it was only possible to proceed to a subsequent questionnaire once all questions in the current questionnaire had been answered. All questions were in multiple-choice format. A percentage of participants received gifts cards, using a lucky draw. Adolescents and young adults were provided with contact information that enabled them to contact the research team if they had any questions or concerns regarding the topics raised in the questionnaires.

\section{Analysis}

A factor analysis with factorisation by principal axes and an orthogonal varimax rotation was used to investigate the internal structure of the RFQ-Y. The orthogonal rotation was chosen in order to obtain independent factors. RFQ-Y raw scores were used in the factor analysis. The Kaiser-Meyer-Olkin (KMO) measure of sampling accuracy and the Bartlett test of sphericity were used to assess the adequacy of the correlation matrices for factor analysis. The Cattell scree test was used to determine the number of factors to retain. Cronbach's alpha was used as a measure of the internal consistency of the items in each factor. Pearson correlations were calculated to assess the relationships between RFQ-Y factors and the MASC subscales (accurate mentalization, hypermentalization, undermentalization and no mentalization), as well as between RFQ-Y factors and BPFS-C, YSR and PNI-A scores. Significance levels were set at $a=.05$. Finally, linear regression analyses were used to examine which dimensions of mentalizing of the RFQ-Y and the MASC have the strongest relationship with psychopathology. MASC scales and 
RFQ-Y factors were entered simultaneously in the models as predictors. The dependant variables were externalizing and internalizing difficulties, borderline personality traits, grandiose narcissism and vulnerable narcissism. All analyses were conducted using IBM Statistics Package for the Social Science (SPSS) v.23.

\section{RESULTS}

\section{Factor structure of the RFQ-Y}

A factor analysis using the principal axis factoring method and an orthogonal varimax rotation was first used to examine the internal structure of the questionnaire. Criteria for exploratory factor analyses were met. Data was distributed normally and no multicollinearity problems were detected. Among the 533 observations collected with the RFQ-Y, using the Mahanalobis distance, with a threshold of $0.1 \%, 25$ observations were excluded because they represented extreme multivariate data $\left(\chi^{2}>86.66\right)$.

\section{$<$ INSERT TABLE 1 ABOUT HERE >}

A value greater than the recommended cut-off of .6 was obtained on the KMO measure of sampling accuracy $(\mathrm{KMO}=.861)$ and the Bartlett test was significant $(p<.001)$, confirming that the correlation matrices were suitable for factor analysis. Results from the factor analysis are presented in Table 1. Initially, five factors emerged from the factor analysis, with factors 4 and 5 explaining less than 5\% of the variance. Results from Cattell's scree test showed that three factors best explained the variance in the data. After rotation, the three factors explained $28.26 \%$ of the total variance. Only items with correlations of more than .40 on a single factor were retained, and in this basis 25 items were retained falling into three factors. Items 1, 3, 4, 5, 6, 7 , 
$12,15,18,21,24,26,28,31,33,39,42$ and 43 were discarded as they did not meet the correlation threshold for any of the three factors. Items 13 and 44 correlated with more than one factor and thus were also discarded. Once aberrant items were removed, a second exploratory factor analysis was performed and still showed a three-factor structure that explained, this time, $39.31 \%$ of the total RFQ-Y variance.

The first factor was named uncertainty/confusion regarding mental states (eigenvalue = 6.41), because all items loading on this factor were related to confusion regarding the mental states of self or others or of a difficulty in identifying self and others' mental states. This factor contains 11 items. As item 8 was negatively correlated with the uncertainty/confusion factor, its scoring was reversed so that an elevated score on this item corresponded to a higher level of confusion regarding mental states. The second factor was named interest/curiosity about mental processes (eigenvalue $=3.63$ ), as this factor emphasized the respondents' interest in mental states as well as their motivation to identify mental states underlying behaviour. Eight items were grouped within this factor. Among these, the scoring of item 14 was reversed due to a negative correlation with this factor so that a higher score on this item maybe indicative of higher interest/curiosity. The third factor was called excessive certainty regarding the mental states of others (eigenvalue $=3.045$ ). This factor comprised items pertaining to respondents' confidence in their knowledge of others' mental states and consisted of 6 items.

\section{$<$ INSERT TABLE 2 ABOUT HERE $>$}

Results from the factor analysis were not consistent with the two scale structure the RFQ$\mathrm{Y}$ is assumed to have. Indeed, most items of the original scale B loaded on the interest/curiosity factor while most items of the original scale A loaded on the confusion factor or the excessive 
certainty factor. Thus, an alternate scoring method was used whereby factor totals were calculated by summing and then averaging the raw scores of the items for each factor. Factor totals were normally distributed. Furthermore, internal consistency was as follows: $a=.89$ for factor $1, a=.75$ for factor 2 , and $a=.80$ for factor 3 .

\section{Associations between the RFQ-Y Factors, the MASC and psychopathology}

The first factor, uncertainty/confusion regarding the mental states, did not correlate with any of the MASC scales (see table 3 for results). The second factor, interest/curiosity, was significantly positively correlated to the accurate mentalization $(r=.35)$ and was significantly negatively correlated with the hypermentalization $(r=-.23)$, undermentalization $(r=-.31)$ and no mentalization $(r=-.27)$ scales. A higher score on the second factor was associated with better overall performance on the MASC and with less mentalizing errors in general. The third factor, excessive certainty, was significantly but weakly negatively correlated with the undermentalization scale $(r=-.18)$. No other significant correlation was observed between excessive certainty and the MASC scales.

\section{<INSERT TABLE 3 ABOUT HERE>}

The uncertainty/confusion factor was significantly positively correlated with all three measures of psychopathology, including the BPFS-C (total score $r=.76$ ), the YSR (internalizing $r=.57$ and externalizing $r=.55$ ) and the PNI-A (grandiose $r=.36$ and vulnerable $r=.51$ ). The factor Interest/curiosity was significantly negatively correlated with borderline traits $(r=-.20)$ as well as with YSR externalizing $(r=-.24)$. However, no significant associations between the factor Interest/curiosity and YSR internalizing or PNI-A subscales were found. A moderate significant positive correlation was found between the third factor, Excessive Certainty, and 
grandiose narcissism $(r=.25)$. All further correlations between this factor and other indices of psychopathology were non-significant.

\section{<INSERT TABLE 4 ABOUT HERE>}

\section{Multivariate regression analysis}

All predictors (4 MASC scales and RFQ-Y factors) were all entered in the models at once to determine which aspects of mentalization best predicted adolescent psychological difficulties and personality functioning. Five different regression models were tested. The dependent variables were internalizing difficulties, externalizing difficulties, borderline personality traits, grandiose narcissism and vulnerable narcissism. The results are presented in table 5.

First, for internalizing difficulties, the regression was significant $F(7,143)=13.43, p<$ .01 , with an $R^{2}$ of 36.7. Only the MASC no mentalization scale $(\beta=-.258, p=.02)$ and RFQ-Y uncertainty/confusion $(\beta=.58, p<.01)$ were significant predictors of internalizing difficulties. For externalizing difficulties, the seven-predictor model was able to account for $34.2 \%$ of variance, $F(7,143)=12.15, p<.01, R^{2}=.64$. Among predictors entered in the model, only RFQ-Y uncertainty/confusion $(\beta=.51, p<.01)$ and interest/curiosity $(\beta=-.243, p<.01)$ made significant unique contributions. A significant regression equation was also found for borderline personality traits, $F(7,143)=32.61, p<.01, R^{2}=.596$. Three predictors made a significant contribution to the regression: RFQ-Y uncertainty/confusion $(\beta=.728, p<.01)$ and RFQ-Y interest/curiosity $(\beta=-.124, p=.03)$, as well as MASC hypermentalization $(\beta=.15, p=.049)$. Finally, for pathological narcissism, the seven-predictor model accounted for $17.9 \%$ of variance in grandiose narcissism, $F(7,143)=5.69, p<.01$, and $38.8 \%$ of vulnerable narcissism, $F(7$, $143)=14.57, p<.01$. The only significant predictor of vulnerable narcissism was the RFQ-Y 
confusion factor $(\beta=.59, p<.01)$. However, a marginally significant relationship was also observed between MASC hypermentalization and vulnerable narcissism $(\beta=.17, p=.07)$. For grandiose narcissism, RFQ-Y uncertainty/confusion $(\beta=.37, p<.01)$ and excessive certainty $(\beta$ $=.22, p<.01)$ made significant contributions to predicting variance in grandiose narcissism.

\section{<INSERT TABLE 5 ABOUT HERE>}

\section{DISCUSSION}

The aim of the present study was to further investigate the psychometric properties of the RFQ-Y in a community sample of French-speaking adolescents. Objectives were to examine the factor structure of the RFQ-Y, and its construct validity via its association with indicators of adolescent psychopathology, and its relationship with another measure of mentalization from a social cognition perspective, the Movie for the Assessment of Social Cognition (MASC; Dziobek et al., 2006). A further objective was to examine which dimensions of mentalizing difficulties identified by the RFQ and the MASC have the strongest relationship with specific clinical problems.

Based on exploratory factor analyses, the 46-item original questionnaire was reduced to 25 items comprising three underlying factors: (1) uncertainty/confusion about mental states (2) interest/curiosity about mental states, and (3) excessive certainty about the mental states of others. Conceptually, these factors resemble the scales of the Parental RF questionnaire (Luyten et al., 2017) which assesses pre-mentalizing modes, certainty about the mental states of the infant, and interest and curiosity in the mental states of the infant. Furthermore, the findings of the factor analyses showed that the majority of the items of scale-A, when coded using a continuous scale (rather than the scoring which assigned an equal value to both extremes), fell 
into the uncertainty/confusion and excessive certainty about mental states factors. For example, the items "I often get confused about what I'm feeling" and "I usually know exactly what other people are thinking" were originally both part of scale A, but now grouped under the uncertainty/confusion factor and the excessive certainty factor. Using a continuous scoring of scale A items thus made it possible to distinguish two types of poor mentalizing including uncertainty/confusion about mental states and excessive certainty about mental states.

Uncertainty/confusion was very strongly positively correlated with BPD traits, moderately correlated with internalizing behaviors, externalizing behaviors, and vulnerable narcissism, and to a lesser extend with grandiose narcissism. This suggests that difficulties in identifying and understanding mental states and feelings and resulting confusion about mental states, is a general risk factor associated with a range of psychological difficulties in adolescents. The uncertainty/confusion factor is particularly interesting, because it shows that adolescents are aware of and identify this confusion when asked questions that specifically tap into these difficulties using self-report measures. RFQ-Y uncertainty/confusion did not correlate with any of the social cognition dimensions assessed with the MASC, suggesting that the uncertainty/confusion factor captures a different dimension of mentalization. This extends previous findings linking low RF in children and adolescents, as measured with the CRFS or the ARFS with internalizing and externalizing difficulties (Ensink et al., 2016; Ha et al., 2013; Taubner et al., 2013). Our findings are also consistent with the relationships found between uncertainty about mental states, measured with the brief version of RFQ, and internalizing and externalizing behaviors and borderline personality traits in adolescents (Badoud et al., 2015). The initial validation study of the RFQ-Y also showed that low RF was associated with more borderline personality traits (Ha et al., 2013). 
There were significant inverse correlations between interest/curiosity and symptoms of BPD, as well as externalizing difficulties. This suggests that interest/curiosity and the motivation to think of mental states underlying behaviors is linked to better regulation of impulses and emotion behavior. The interest/curiosity factor includes items that seem to capture an interest in or a motivation to think of and understand mental states (of self and others). Mentalization is usually thought of as the capacity to identify mental states underlying behaviors (Fonagy et al., 2002) and we tend to overlook the implicit component of interest or motivation to think about mental states. Interest and motivation to think about mental states are likely to facilitate developing good mentalizing and using it once you have developed it. It is likely that curiosity about mental states denotes an attitude or a stance that is key in good mentalizing. In line with this, there were significant correlations in the expected direction between interest/curiosity and all the MASC scales; there was a positive correlation with good mentalizing scale assessed with the MASC and significant inverse correlations with hypermentalization, undermentalisation and absence of mentalization.

The third factor assesses excessive certainty about mental states of others and difficulties recognizing what Fonagy has referred to as the opacity of mental states; although we may have a pretty good sense of what others are thinking and feeling, it is not possible to know this with complete certainty. Even with good mentalizing capacities, we can sometimes make wrong assumptions, or misread the expressions of others. Excessive certainty was positively correlated with grandiose narcissism, extending the findings of Ames and Kammrath's (2004) and of Ritter and colleagues' (2011) showing that narcissistic individuals tend to overestimate their mentalizing abilities. However, our results suggest that the excessive certainty about mental states or the overestimation of mentalizing abilities is specifically linked to the grandiose 
dimension of narcissism. Adolescents who obtain high scores on excessive certainty are likely to assume that they can know with certainty what others' feel and intend and don't consider that they could be wrong. Excessive certainty is likely to be associated with mentalizing errors because there is not an automatic taking into account of the fact that their affects may have an impact on the way they interpret what others are doing or they awareness that they could be mistaken about their attributions, or that they need to check their perceptions with others. There was a significant inverse correlation between excessive certainty and undermentalizing, measured with the MASC, consistent with the observation that excessive certainty involves active mentalizing, but of a particular erroneous type.

The findings of the regression analyses showed that a combination of RFQ-Y and MASC scales predicted adolescent psychological difficulties and personality disorders. Internalizing difficulties were predicted by more uncertainty/confusion about mental states on the RFQ-Y and absence of mentalization on the MASC, whereas externalizing difficulties were predicted by more uncertainty/confusion and less interest/curiosity in mental states on the RFQ-Y. Borderline personality traits were predicted by more uncertainty/confusion and lower interest/curiosity on the RFQ-Y, as well as by hypermentalizing on the MASC. For pathological narcissism, excessive certainty about mental states, as well as uncertainty/confusion on the RFQ-Y were significant predictors of grandiose narcissism, while uncertainty/confusion on the RFQ-Y and hypermentalizing on the MASC (at a marginal level of significance) predicted vulnerable narcissism. This suggests that uncertainty/confusion measured with the RFQ-Y may be a general risk factor which is associated with internalizing and externalizing psychopathology, as well as personality disorders. Furthermore, the findings suggest that both the RFQ-Y and MASC scales identify distinct mentalizing difficulties that make independent contributions to predicting 
psychological and personality difficulties in adolescence. Both measures appear to assess distinct and important dimensions of mentalization, and when used in a complementary fashion, can potentially help to identify combinations of mentalizing difficulties associated with different types of psychological problems. For example, the findings of the regression analysis suggest that BPD uncertainty/confusion and interest/curiosity assessed with the RFQ-Y and hypermentalization assessed on the MASC. This adds to the findings of previous studies that identified hypermentalization as being more specific to BPD in adolescents (Sharp et al., 2011; Sharp et al., 2013) by showing that other types of mentalization difficulties such as uncertainty/ confusion and lack of interest and curiosity also contribute to the problems associated with BPD. The similarities between the predictors of BPD and vulnerable narcissism found in the present study are consistent with findings from other studies where significant overlaps between these two pathologies were found (Miller et al., 2010), although the findings of the present study suggest that more types of difficulties in mentalizing are associated with BPD than with vulnerable narcissism.

In our study, the interest/ curiosity factor appeared to capture a dimension of good mentalization, while the uncertainty/confusion factor tapped into insufficient knowledge and confidence in mentalizing and having a sense of what others feel or think, while excessive certainty appeared to tap into a problematic excessive confidence in mentalizing capacities. The three factors identified in the study can be seen as fitting broadly into a model where there is a $\mathrm{U}$ shaped relationship between mentalizing and psychopathology, and where mentalizing difficulties associated with psychopathology and personality disorders may manifest as either undermentalizing and confusion/uncertainty, or by hypermentalizing or excessive certainty, while good mentalizing or interest/curiosity is associated with better adaptive functioning. This 
is consistent with the general model of social cognition proposed by Perez-Rodriguez and colleagues (2014) where undermentalization was found to be more frequent in clinical populations with autism or schizophrenia, while hypermentalization was more frequent in clinical populations with BPD (Sharp et al., 2011; Sharp et al., 2013). Building on this model, our findings in a nonclinical population suggest that confusion/uncertainty, interest/curiosity and excessive certainty are three dimensions of mentalizing relevant for understanding mentalizing difficulties associated with different psychological problems.

With respect to the strengths and limitations of this study, it was the first study, to our knowledge, to use the RFQ-Y in a relatively large sample of adolescents from the community, thus complementing the previous study on the validity of the RFQ-Y that was carried out with an inpatient sample of adolescents (Ha et al., 2013). The inclusion of the MASC in this study made it possible to examine the relationships between RFQ-Y and performance on a mentalizing task that was also developed to capture dimensions of both good mentalizing as well as different types of mentalizing errors. However, only a sub-sample of participants completed the MASC and it was the only measure of construct validity included in the study. Another limitation of the study was that there was a relatively higher proportion of girls compared to boys in the present sample. Future studies should further investigate construct validity of our three factors by including questionnaires which measure different aspects of mentalization, like empathy, alexithymia or mindfulness. Moreover, further research is needed to determine whether the RFQ-Y factors identified in the present study can be replicated in other samples. 
The findings demonstrate that the RFQ-Y has good psychometric properties and underscore the utility of measuring RF using self-report measures. Three factors were identified, including uncertainty/confusion about mental states, interest/curiosity about mental states and excessive certainty about mental states. All three were shown to be related to psychological difficulties and personality disorders. Uncertainty/confusion regarding mental states correlated very strongly with BPD, internalizing and externalizing difficulties, as well as with vulnerable narcissism and to a lesser extend to grandiose narcissism. The findings suggest that uncertainty/confusion regarding mental states may be a general vulnerability factor associated with psychopathology. At the same time, overcertainty regarding mental states emerged as a style of mentalizing associated with grandiose narcissism. The RFQ-Y dimensions correlated more strongly with psychopathology than the MASC, suggesting that the measure is able to tap into distinct mentalizing difficulties particularly relevant to psychological difficulties and personality disorders. In sum, the findings demonstrate that self-report measures like the RFQ-Y are potentially helpful for understanding and identifying problematic mentalizing that have implications for clinical intervention. 


\section{ABOUT THE AUTHORS}

Josée Duval, B. A. completed the research reported here in partial fulfillment towards her PhD degree in Clinical Psychology at University Laval. Her interests include the assessment of mentalization in children and adolescents, and the clinical applications of mentalization.

Karin Ensink, Ph. D. is Professor of Child and Adolescent Psychology at University Laval. Her research focuses on mentalization, trauma, and personality in pathways to psychopathology and clinical applications. She is developer of MBT for children and Transference Focused Psychotherapy for borderline adolescents.

Lina Normandin, Ph. D. is Professor of Child and Adolescent Psychology at University Laval and her research and clinical work focus on personality orders, their early manifestations as well as Transference Focused Psychotherapy for borderline adolescents.

Carla Sharp, Ph. D. is Professor of Psychology at the University of Houston. She is a developmental psychopathologist with an interest in social cognition as a correlate, cause and treatment target for mental health problems in youth.

Peter Fonagy, Ph. D. is Professor of Contemporary Psychoanalysis and Developmental Science, and is also Chief Executive of The Anna Freud Centre. He developed Mentalization-Based Treatment (MBT) for adults and adolescents with borderline personality disorders. 


\section{List of Abbreviations}

ARFS: Adult Reflective Functioning Scale

BPD: Borderline personality disorder

BPFS-C: Borderline Personality Features Scale for Children

CARFS: Child and Adolescent Reflective Functioning Scale

KMO: Kaiser-Meyer-Olkin

MASC: Movie Assessment of Social Cognition

MBT: Mentalization-based treatment

PAI: Personality Assessment Inventory

PNI-A: Pathological Narcissism Inventory for Adolescents

PRFS: Parental Reflective Functioning Scale

RF: Reflective functioning

RFQ: Reflective Functioning Questionnaire

RFQ-Y: Reflective Functioning Questionnaire for Youth

SPSS: Statistical Package for the Social Sciences

YSR: Child Behavior Checklist - Youth Self-report 


\section{CONFLICTS OF INTEREST}

The authors of this study declare that they have no biomedical or financial conflicts of interest to disclose.

\section{ACKNOWLEDGMENTS}

Peter Fonagy is in receipt of a National Institute for Health Research (NIHR) Senior Investigator Award (NF-SI-0514-10157). Peter Fonagy was in part supported by the NIHR Collaboration for Leadership in Applied Health Research and Care (CLAHRC) North Thames at Barts Health NHS Trust. The views expressed are those of the authors and not necessarily those of the NHS, the NIHR or the Department of Health.

\section{REFERENCES}

Achenbach, T. (1991). Manual for the Youth Self-Report and 1991 profile. Department of Psychiatry University of Vermont: Burlington.

Allen, J. G., Fonagy, P., \& Bateman, A. L. (2008). Mentalizing in Clinical Practice. American Psychiatric Publishing.

Ames, D. R., \& Kammrath, L. K. (2004). Mind-reading and metacognition: narcissism, not actual competence, predicts self-estimated ability. Journal of Nonverbal Behavior, 28, 187-209.

Badoud, D., Luyten, P., Fonseca-Pedrero, E., Eliez, S., Fonagy, P., \& Debanné, M. (2015). The French version of the Reflective Functioning Questionnaire: Validity data for adolescents and adults and its associations with non-suicidal self-injury. PloS One, 10, e0145892. doi:10.1371/journal.pone.0145892 
Bateman, A., \& Fonagy, P. (2010). Mentalization based treatment for borderline personality disorder. World Psychiatry, 9, 11-15. doi: 10.1002/j.2051-5545.2010.tb00255x

Bateman, A., \& Fonagy, P. (2004). Psychotherapy for borderline personality disorder: Mentalization based treatment. Oxford: Oxford University Press.

Bégin, M., Ensink, K., Kotiuga, J., Leclerc, C., Thériault-Sereno, A., \& Normandin, L. (2017). The borderline personality feature scale for children and adolescents; psychometric of the French version. Psychological Assessment (submitted).

Benbassat, N., \& Priel, B. (2012). Parenting and adolescent adjustment : the role of parental reflective function. Journal of Adolescence, 35, 163-174. doi:10.1016/j.adolescence.2011.03.004

Braehler, C., \& Schwannauer, M. (2012). Recovering an emerginf self: exploring reflective function in recovery from adolescent-onset psychosis. Psychology and Psychotherapy, 85, 48-67. doi: 10.1111/j.2044-8341.2011.02018.x.

Bossé-Chartier, G. (2013). Fonctionnement émotionnel et social des adolescents dépressifs, de leur fratrie et d'un groupe témoin: étude tranversale. (Unpublished master's thesis). University of Montreal.

Buhlmann, U., Wacker, R., \& Dziobek, I. (2015). Inferring other people's states of mind: Comparison across social anxiety, body dysmorphic, and obsessive-compulsive disorders. Journal of Anxiety Disorders, 34, 197-113. Doi: 10.1016/j.janxdis.2015.06.003

Chrétien, S., Ensink, K., Descoteaux, J. \& Normandin, L. (2017). Measuring grandiose and vulnerable narcissism in adolescents. Assessment (submitted). 
Crick, N. R., Murray-Claose, D., \& Woods, K. (2005). Borderline personality features in childhood: a short-term longitudinal study. Development and Psychopathology, 17, 10511070.

Dziobek, I., Fleck, S., Kalbe, E., Rogers, K, Hassenstab, J., Brand, M., ... Convit, A. (2006). Introducing MASC: a movie for the assessment of social cognition. Journal of Autism and Developmental Disorders, 36, 623-636. doi: 10.1007/s10803-006-0107-0

Ensink, K., Bégin, M., Normanding, L., \& Fonagy, P. (2016). Maternal and child reflective functioning in the context of child sexual abuse: pathways to depression and externalizing difficulties. European Journal of Psychotraumatology, 7, 30611. doi: 10.3402/ejpt.v7.30611

Ensink, K., Chrétien, S., Daigle, D., Normandin, L., Bégin, M., \& Fonagy, P. (2017). Pathological narcissism in adolescents: relationships with childhood maltreatment and internalizing and externalizing difficulties. Adolescent Psychiatry.

Ensink, K., Normandin, L., Plamondon, A., Berthelot, N., \& Fonagy, P. (2016). Intergenerational pathways from reflective function to infant attachment through parenting. Canadian Journal of Behavioral Science, 48, 9-18. doi: 10.1037/cbs0000030.

Ensink, K., Normandin, L., Target, M., Fonagy, P., Sabourin, S., \& Berthelot, N. (2015). Mentalization in children and mothers in the context of trauma: An initial study of the validity of the Child Reflective Functioning Scale. The British Journal of Developmental Psychology, 33, 203-217. doi: 10.1111/bjdp.12074. 
Ensink, K., Target, M., Oandasan, C., \& Duval, J. (2016). Child and Adolescent Reflective Functioning Scale scoring manual: For application to the Child Attachment Interview. United Kingdom: Anna Freud Centre - University College London.

Fischer-Kern, M., Fonagy, P, Kapusta, N. D., Luyten, P., Boss, S., Naderer, A., Bluml, V., \& Leithner, K. (2013). Mentalizing in female inpatients with major depressive disorder. Journal of Nervous and Mental Disease, 201, 202-207. doi:10.1097/NMD.0b013e3182845c0a

Fonagy, P. (2008). Mentalization: theoretical implications, research findings, and clinical implication. In The mentalization-focused approach to social development (p.3-56). New York: Analytic Press.

Fonagy, P. (2004). Early-life trauma and the psychogenesis of violence. Annals of the New York Academy of Sciences, 1036, 181-200. doi: 10.1196/annals.1330.012

Fonagy, P. Gergely, G., Jurist, E. L., \& Target, M. (2002). Affect regulation, mentalization and the development of the self. New York, NY: Other Press.

Fonagy, P., \& Ghanai, R. A self-report measure of mentalizing: Development and preliminary test of the reliability and validity of the Reflective Function Questionnaire (RFQ). Unpublished manuscript. UK: University College London.

Fonagy, P., \& Luyten, P. (2016). A multilevel perspective on the development of borderline personality disorder. In D. Cicchetti (ed), Developmental psychopathology, Vol. 3: Risk, disorder and adaptation ( $3^{\text {rd }}$ ed, vol. 3, p. 726-792). New York, NY: John Wiley \& Sons. 
Fonagy, P., \& Luyten, P. (2009). A developmental, mentalization-based approach to the understanding and treatment of borderline personality disorder. Development Psychopathology, 21, 1355-1381. doi: 10.1017/S0954579409990198.

Fonagy, P., Luyten, P., Moulton-Perkins, A., Lee, Y., Warren, F., Howard, S., .. Lowyck, B. (2016). Development and validation of a self-report measure of mentalizing: The reflective function questionnaire. PLos One, 11, doi: 10.1371/journal.pone.0158678.

Fonagy, P., Steele, M., Steele, H., \& Target, M. (1998). Reflective functioning manual: Version 5.0 for the application to the Adult Attachment Interview. London: University College.

Fonagy, P., \& Target, M. (1997). Attachment and reflective function: their role in selforganization. Development and Psychopathology, 9, 679-700.

Grienenberger, J. F., Kelly, K., \& Slade, A. (2005). Maternal reflective functioning, motherinfant affective communication, and infant attachment: exploring the link between mental states and observed caregiving behavior in the intergenerational transmission of attachment. Attachment \& Human Development, 7, 299-311. doi:10.1080/14616730500245693

Ha, C., Sharp, C., Ensink, K., Fonagy, P., \& Cirino, P. (2013). The measurement of reflective function in adolescents with and without borderline traits. Journal of Adolescence, 36, 1215-1223. doi: 10.1016/j.adolescence.2013.09.008.

Luyten, P., Mayes, L. C., Nijssens, L., \& Fonagy, P. (2017). The parental reflective functioning questionnaire: Development and preliminary validation. PLoS One, 12, e0176218. doi:10.1371/journal.pone.0176218 
Miller, J. D., Dir, A., Gentile, B., Wilson, L., Pryor, L. R., \& Campbell, W. K. (2010). Searching for a vulnerable dark triad: Comparing factor 2 psychopathy, vulnerable narcissism, and borderline personality disorder. Journal of Personality, 78, 1529-1564. doi: 10.1111/j.1467-6494-2010.00660.x

Montag, C., Dziobek, I., Richter, I. S., Neuhaus, K., Lehmann, A., Sylla, R., ... Gallinat, J. (2011). Different aspects of theory of mind in paranoid schizophrenia: evidence from a video-based assessment. Psychiatry Research, 186, 203-209. doi: 10.1016/j.psychres.2010.09.006.

Montag, C., Ehrlich, A., Neuhaus, K., Dziobek, I., Heekeren, H. R., Heinz, A., \& Gallinat, J. (2010). Theory of mind impairments in euthymic bipolar patients. Journal of Affective Disorders, 123, 264-269. doi: 10.1016/j.jad.2009.08.017

Morey, L. (1991). The Personality Assessment Inventory: Professional manual. Lutz, FL: Psychological Assessment Resources.

Perez-Rodriguez, M. M., Mahon, K., Russo, M., Ungar, A. K., \& Burdick, K. E. (2014). Oxytocin and social cognition in affective and psychotic disorders. European Neuropsychopharmacology. doi : 10.1016/j.euroneuro.2014.07.012

Pincus, A. L., Ansell, E. B., Pimentel, C. A., Cain, N. M., Wirght, A. G. C., Levy, K. N. (2009). Initial construction and validation of the Pathological Narcissism Inventory. Psychological Assessment, 21, 365-379. doi: 10.1037/a0016530. 
Pöttgen, J., Dziobek, I., Reh, S., Heesen, C., \& Gold, S. M. (2013). Impaired social cognition in multiple sclerosis. Journal of Neurology, Neurosurgery, and Psychiatry, 84, 523-528. doi: 10.1136/jnnp-2012-304157.

Preissler, S., Dziobek, I., Ritter, K., Heekeren, H. R., \& Roepke, S. (2012). Social cognition in borderline personality disorder: evidence for disturbed recognition of the emotions, thoughts, and intentions of others. Frontiers in behavioral neuroscience, 4, 1-8. doi:10.3389/fnbeh.2010.00182

Ritter, K., Dziobek, I., Preibler, S., Rüter, A., Vater, A., Fydrich, T., ... Roepke, S. (2011). Lack of empathy in patients with narcissistic personality disorder. Psychiatric Research, 187, 241-247. doi: 10.1016/j.psychres.2010.09.013.

Sharp, C., Fonagy, P., \& Goodyear, I. M. (2008). Social cognition and developmental psychopathology. Oxford: Oxford University Press.

Sharp, C., Ha, C., Carbone, C., Kim, S., Perry, K., Williams, L., \& Fonagy, P. (2013). Hypermentalizing in adolescent inpatients: treatment effects and association with borderline traits. Journal of Personality Disorders, 27, 3-18. doi: 10.1521/pedi.2013.27.1.3.

Sharp, C., Pane, H., Ha, C., Venta, A., Patel, A. B., Sturek, J., \& Fonagy, P. (2011). Theory of mind and emotion regulation difficulties in adolescents with borderline traits. Journal of the American Academy of Child and Adolescent Psychiatry, 50, 563-573. doi:10.1016/j.jaac.2011.01.017 
Skarderud, F. (2007a). Eating one's words, part II: The embodied mind and reflective function in anorexia nervosa theory. European Eating Disorders Review, 15, 243-252.

Skarderud, F. (2007b). Eating one's words: Part III. Mentalization-based psychotherapy for anorexia nervosa - an outline for a treatment and training manual. European Eating Disorders Review, 15, 323-339.

Slade, A., Bernbach, E., Grienenberge, J., Levy, D., \& Locker, A. (2005). Addendum to reflective functioning scoring manual for use with the Parent Development Interview. Unpublished manuscript.

Slade, A., Grienenberge, J., Bernbach, E., Levy, D., \& Locker, A. (2005). Maternal reflective functioning, attachment, and the transmission gap: a preliminary study. Attachment \& Human Development, 7, 283-298. doi: 10.1080/14616730500245880

Stacks, A. M., Muzik, M., Wong, K., Beeghly, M., Huth-Bocks, A., Irwin, J. L., \& Rosenblum, K. L. (2014). Maternal reflective functioning among mothers with childhood maltreatment histories: links to sensitive parenting and infant attachment security. Attachment \& Human Development, 16, 515-533. doi: 10.1080/14616734.2014.935452

Steele, H., Steele, M., Croft, C., \& Fonagy, P. (1999). Infant-mother attachment at one year predicts children's understanding of mixed emotions at six years. Social Development, 8 , 161-178. doi: 10.1111/1467-9507.00089

Taubner, S., White, L. O., Zimmermann, J., Fonagy, P., \& Nolte, T. (2013). Attachment-related mentalization moderates the relationship between psychopathic traits and proactive 
aggression in adolescence. Journal of Abnormal Child Psychology, 41, 929-938. doi:10.1007/s10802-013-9736-х

Wolkenstein, L, Schönenberg, M., Schirm, E., \& Hautzinger, M. (2011). I can see what you feel, but I can't deal with it: Impaired theory of mind in depression. Journal of Affective Disorders, 132, 104-111. doi:10.1016/j.jad.2011.02.010 
Table 1

Descriptive statistics of the sample

\begin{tabular}{lllll}
\hline Variable & $\mathrm{N}$ & Mean $(\mathrm{SD})$ & Minimum & Maximum \\
\hline Age & 533 & $16,94(3,91)$ & 12 & 21 \\
RFQ-Y factor 1 & 533 & $3,13(0,95)$ & 1 & 5,91 \\
RFQ-Y factor 2 & 533 & $4,48(0,69)$ & 1,75 & 6 \\
RFQ-Y factor 3 & 531 & $3,52(0,85)$ & 1,17 & 6 \\
BPFS-C (total) & 374 & $54,86(14,60)$ & 26 & 99 \\
YSR internalizing & 339 & $59,37(11,53)$ & 30 & 86 \\
YSR externalizing & 340 & $50,63(8,56)$ & 29 & 75 \\
PNI grandiose & 447 & $3,19(0.66)$ & 1,19 & 5,69 \\
PNI vulnérable & 447 & $3,12(0.84)$ & 1,12 & 5,62 \\
MASC accurate & 150 & $32,39(9,04)$ & 6 & 44 \\
MASC hyper & 150 & $6,78(3,93)$ & 0 & 20 \\
MASC under & 150 & $6,39(3,03)$ & 0 & 15 \\
MASC no & 150 & $2,68(3,24)$ & 0 & 17 \\
\hline
\end{tabular}

Abbreviations : RFQ-Y : Reflective Function Questionnaire for Youth, BPFS-C (total) = Bordeline Personality Features Scale for Children, total, YSR: Youth Self Report, internalizing= internalizing behavior, externalizing = externalizing behavior, PNI : Pathological Narcissism Inventory, MASC: Movie for the Assessment of Social Cognition, accurate $=$ accurate mentalization, hyper $=$ hypermentalization, under = undermentalization and no $=$ no mentalization. 
Table 2

\section{$R F Q-Y$ factor loadings after rotation}

\begin{tabular}{|c|c|c|c|c|}
\hline Factors and items & F1 & F2 & F3 & Communalities \\
\hline \multicolumn{5}{|l|}{ F1 Uncertainty/confusion about mental states } \\
\hline 36. Sometimes I do things without really knowing why. & .75 & -.05 & -.03 & $\Sigma \mathrm{a}^{2}=.57$ \\
\hline $\begin{array}{l}\text { 38. Sometimes I find myself saying things and I have no idea why I said } \\
\text { them. }\end{array}$ & .73 & -.09 & -.02 & $\Sigma \mathrm{a}^{2}=.54$ \\
\hline 17. I don't always know why I do what I do. & .71 & .01 & .02 & $\Sigma \mathrm{a}^{2}=.50$ \\
\hline 10. I often get confused about what I am feeling. & .69 & .14 & -.14 & $\Sigma \mathrm{a}^{2}=.52$ \\
\hline $\begin{array}{l}\text { 23. Those close to me often seem to find it difficult to understand why I do } \\
\text { things. }\end{array}$ & .66 & -.04 & .12 & $\Sigma \mathrm{a}^{2}=.45$ \\
\hline 35. If I feel unsure of myself, I can behave in ways that offend others. & .63 & -.04 & .06 & $\Sigma \mathrm{a}^{2}=.40$ \\
\hline 27. Strong feelings often cloud my thinking. & .62 & .09 & .03 & $\Sigma \mathrm{a}^{2}=.39$ \\
\hline 29. When I get angry I say things that I later regret. & .61 & -.06 & .05 & $\Sigma \mathrm{a}^{2}=.38$ \\
\hline $\begin{array}{l}\text { 22. When I get angry I say things without really knowing why I am saying } \\
\text { them. }\end{array}$ & .60 & -.09 & .03 & $\Sigma \mathrm{a}^{2}=.37$ \\
\hline 8. I always know what I feel. & -.48 & -.04 & .21 & $\Sigma \mathrm{a}^{2}=.28$ \\
\hline 9. I feel that, if I'm not careful, I could get in the way of another person's & .48 & .05 & .07 & $\Sigma \mathrm{a}^{2}=.24$ \\
\hline \multicolumn{5}{|l|}{ life. } \\
\hline 44. How I feel easily affect how I understand someone else's behavior. & .46 & .31 & -.01 & $\Sigma \mathrm{a}^{2}=.31$ \\
\hline 13. I get confused when people talk about their feelings. & .41 & -.32 & -.14 & $\Sigma \mathrm{a}^{2}=.29$ \\
\hline 32. I frequently feel that my mind is empty. & .38 & -.15 & -.04 & $\Sigma \mathrm{a}^{2}=.17$ \\
\hline 7. I often have to force people to do what I want them to do & .36 & -.19 & .06 & $\Sigma \mathrm{a}^{2}=.17$ \\
\hline 1. People's thoughts are a secret to me. & .34 & -.05 & -.29 & $\Sigma \mathrm{a}^{2}=.20$ \\
\hline 28. I trust my feelings. & -.33 & .14 & .15 & $\Sigma \mathrm{a}^{2}=.15$ \\
\hline 4. I realize that I can sometimes misunderstand my best friends' reactions. & .32 & .21 & -.11 & $\Sigma \mathrm{a}^{2}=.16$ \\
\hline 3. My picture of my parents changes as I change. & .31 & .27 & -.02 & $\Sigma \mathrm{a}^{2}=.17$ \\
\hline 26. I can't remember much about when I was a child. & .23 & -.02 & -.04 & $\Sigma \mathrm{a}^{2}=.05$ \\
\hline 24. I am better guided by reason than by my gut. & -.20 & .16 & -.01 & $\Sigma \mathrm{a}^{2}=.07$ \\
\hline $\begin{array}{l}\text { 5. I believe that my parents' behavior towards me should not be explained by } \\
\text { how they were raised. }\end{array}$ & .19 & -.02 & -.01 & $\Sigma \mathrm{a}^{2}=.04$ \\
\hline \multicolumn{5}{|l|}{ F2 Interest/Curiosity in mental states } \\
\hline 45. I pay attention to the impact of my actions on others' feelings. & -.22 & .61 & .05 & $\Sigma \mathrm{a}^{2}=.42$ \\
\hline 41. I'm often curious about the meaning behind others' actions. & .04 & .60 & .19 & $\Sigma \mathrm{a}^{2}=.40$ \\
\hline 20. Understanding the reasons for people's action helps me to forgive them. & -.17 & .58 & .10 & $\Sigma \mathrm{a}^{2}=.38$ \\
\hline 14. I believe that other people are too confusing to bother figuring out. & .26 & -.52 & -.09 & $\Sigma \mathrm{a}^{2}=.35$ \\
\hline 2. I worry a lot about what people are thinking and feeling. & .15 & .48 & .05 & $\Sigma \mathrm{a}^{2}=.26$ \\
\hline 19. In an argument, I keep the other person's point of view in mind. & -.29 & .47 & .13 & $\Sigma \mathrm{a}^{2}=.32$ \\
\hline 34. I like to think about the reasons behind my actions. & -.10 & .46 & .06 & $\Sigma \mathrm{a}^{2}=.23$ \\
\hline $\begin{array}{l}\text { 11. I believe that people can see a situation very differently based on their } \\
\text { own }\end{array}$ & -.09 & .43 & .01 & $\Sigma \mathrm{a}^{2}=.20$ \\
\hline \multicolumn{5}{|l|}{ beliefs and experiences. } \\
\hline 15. I find it difficult to see other people's points of view. & .38 & -.38 & -.06 & $\Sigma \mathrm{a}^{2}=.29$ \\
\hline 18. I pay attention to my feelings. & -.32 & .38 & .05 & $\Sigma \mathrm{a}^{2}=.25$ \\
\hline 6. Other people tell me I'm a good listener. & -.30 & .36 & .15 & $\Sigma \mathrm{a}^{2}=.24$ \\
\hline $\begin{array}{l}\text { 33. I predict that my feelings might change even about something I feel } \\
\text { strongly } \\
\text { about. }\end{array}$ & .05 & .34 & -.03 & $\Sigma \mathrm{a}^{2}=.12$ \\
\hline $\begin{array}{l}\text { 42. I have noticed that people often give advice to others that they actually } \\
\text { wish }\end{array}$ & .15 & .34 & .16 & $\Sigma \mathrm{a}^{2}=.16$ \\
\hline to follow themselves. & & & & \\
\hline $\begin{array}{l}\text { 39. In order to know exactly how someone is feeling, I have found that I need } \\
\text { to }\end{array}$ & -.09 & .30 & -.23 & $\Sigma \mathrm{a}^{2}=.19$ \\
\hline $\begin{array}{l}\text { ask them. } \\
\text { 12. I believe there's no point trying to guess what's on someone else' mind. }\end{array}$ & .00 & -.26 & -.23 & $\Sigma \mathrm{a}^{2}=.12$ \\
\hline
\end{tabular}


43. I wonder what my dreams mean.

21. I believe that there is no RIGHT way of seeing any situation.

$\begin{array}{llll}.20 & .24 & .04 & \Sigma \mathrm{a}^{2}=.10\end{array}$

31. For me actions speak louder than words.

$.08 \quad .16$

$-.02$

$\Sigma \mathrm{a}^{2}=.03$

F3 Excessive certainty about mental states of others

16. I am a good mind reader.

.02

$.13 \quad .02$

$\Sigma \mathrm{a}^{2}=.02$

25. I usually know exactly what other people are thinking.

40. I can mostly predict what someone else will do.

46. I know exactly what my close friends are thinking.

37. I can tell how someone is feeling by looking at their eyes.

30. My feelings about a person are hardly ever wrong.

$\begin{array}{llll}-.03 & .17 & .78 & \Sigma \mathrm{a}^{2}=.64\end{array}$

$\begin{array}{llll}-.03 & .08 & .73 & \Sigma \mathrm{a}^{2}=.54\end{array}$

$\begin{array}{rrrr}-.03 & .08 & \mathbf{. 7 3} & \Sigma \mathrm{a}^{2}=.54 \\ 13 & .08 & \mathbf{. 7 0} & \Sigma \mathrm{a}^{2}=.51\end{array}$

$.06 \quad .01$

.55

$\Sigma \mathrm{a}^{2}=.31$

$10 \quad .16$

$-.11$

.16
.07

55

$\Sigma \mathrm{a}^{2}=.34$

$\Sigma \mathrm{a}^{2} \quad \Sigma \mathrm{a}^{2} \quad \Sigma \mathrm{a}^{2}$

Sum of squares after rotation (eigen value)

$6,41 \quad 3,63 \quad 2,96$

$\Sigma \mathrm{a}^{2}=.26$

Proportion of variance

$\begin{array}{lll}.14 & .08 & .06\end{array}$

Proportion of covariance

$\begin{array}{lll}.49 & .28 & .23\end{array}$

Note. The English items are here presented to facilitate the reader's understanding, but the French corresponding items were actually answered by participants. Numbers in bold represent the items that clearly stand out on one of the three factors. 
Table 3

Correlations between RFQ-Y25 factors and MASC scales $(N=150)$

\begin{tabular}{|c|c|c|c|c|c|c|c|}
\hline & 1 & 2 & 3 & 4 & 5 & 6 & 7 \\
\hline $\begin{array}{l}\text { 1. F1 uncertainty } \\
\text { RFQ-Y }\end{array}$ & - & & & & & & \\
\hline $\begin{array}{l}\text { 2. F2 interest } \\
\text { RFQ-Y }\end{array}$ & $-.13 * *$ & - & & & & & \\
\hline $\begin{array}{l}\text { 3. F3 certainty } \\
\text { RFQ-Y }\end{array}$ & .03 & $.25^{* *}$ & - & & & & \\
\hline $\begin{array}{l}\text { 4. MASC } \\
\text { accurate }\end{array}$ & -.04 & $.35 * *$ & .08 & - & & & \\
\hline $\begin{array}{l}\text { 5. MASC } \\
\text { hyper }\end{array}$ & .14 & $-.23 * *$ & -.02 & $-.65 * *$ & - & & \\
\hline $\begin{array}{l}\text { 6. MASC } \\
\text { under }\end{array}$ & -.01 & $-.31 * *$ & $-.18 *$ & $-.66 * *$ & $.21 *$ & - & \\
\hline $\begin{array}{l}\text { 7. MASC } \\
\text { No }\end{array}$ & .05 & $-.28 * *$ & -.04 & $-.78 * *$ & $.36 * *$ & $.56 * *$ & - \\
\hline
\end{tabular}


Table 4

Correlations between RFQ-Y25 factors and psychopathology and between MASC scales and psychopathology

\begin{tabular}{lrrrrr}
\hline & BPD traits & YSR ext. & $\begin{array}{r}\text { YSR } \\
\text { int. }\end{array}$ & $\begin{array}{r}\text { PNI } \\
\text { Gran }\end{array}$ & $\begin{array}{r}\text { PNI } \\
\text { Vul }\end{array}$ \\
\hline Uncertainty & $.76^{* *}$ & $.54^{* *}$ & $.57^{* *}$ & $.36^{* *}$ & $.51^{* *}$ \\
Interest & $-.20^{* *}$ & $-.24^{* *}$ & .01 & .03 & .06 \\
Certitude & .05 & .06 & .04 & $.25^{* *}$ & .06 \\
MASC accurate & -.05 & -.04 & -.004 & .11 & .06 \\
MASC hyper & $.21^{*}$ & .12 & $.17 *$ & .03 & .14 \\
MASC under & -.05 & -.07 & -.15 & -.12 & -.15 \\
MASC no & .03 & -.01 & -.12 & -.11 & -.05 \\
\hline$*_{p<05 * *<01}^{* * 11}$ & & & & &
\end{tabular}

Abbreviations: YSR: Youth Self Report, ext. = externalizing behaviors, int. = internalizing behaviors, PNI: Pathological Narcissism Inventory, Grand $=$ grandiose narcissism, Vul = vulnerable narcissism, MASC: Movie for the Assessment of Social Cognition, accurate $=$ accurate mentalization, hyper $=$ hypermentalization, under $=$ undermentalization and no $=$ no mentalization . 
Table 5 .

Results of linear regression analyses that examine the contributions of RFQ-Y and MASC scales to predict internalizing behaviors, externalizing behaviors, borderline personality traits and pathological narcissism in an adolescent community sample. .

\begin{tabular}{|c|c|c|c|c|c|c|c|c|c|c|c|c|c|c|c|}
\hline & \multicolumn{3}{|c|}{$\begin{array}{c}\text { Externalizing } \\
\text { behaviors }\end{array}$} & \multicolumn{3}{|c|}{$\begin{array}{c}\text { Internalizing } \\
\text { behaviors }\end{array}$} & \multicolumn{3}{|c|}{ BPD traits } & \multicolumn{3}{|c|}{$\begin{array}{l}\text { Vulnerable } \\
\text { narcissism }\end{array}$} & \multicolumn{3}{|c|}{$\begin{array}{l}\text { Grandiose } \\
\text { Narcissism }\end{array}$} \\
\hline & $B$ & $T$ & $P$ & $B$ & $t$ & $P$ & $B$ & $T$ & $p$ & $\beta$ & $T$ & $p$ & $\beta$ & $t$ & $P$ \\
\hline RFQ U/C & .51 & 7.49 & $.000 *$ & .58 & 8.68 & $.000 *$ & .73 & 13.63 & $.000 *$ & .59 & 8.97 & $.000 *$ & .37 & 4.86 & $.000 *$ \\
\hline RFQ I/C & -.24 & -3.41 & $.001 *$ & -.02 & -.26 & .798 & -.12 & -2.22 & $.028 *$ & -.04 & -.57 & .567 & .002 & .02 & .982 \\
\hline RFQ certitude & .03 & .36 & .718 & -.003 & -.05 & .963 & .01 & .09 & .931 & .05 & .68 & .499 & .22 & 2.89 & $.004 *$ \\
\hline MASC accurate & -.19 & -1.22 & .226 & -.25 & -1.63 & .105 & .06 & .51 & .614 & .15 & .98 & .330 & .13 & .77 & .442 \\
\hline MASC hyper & -.03 & -.33 & .745 & .06 & .59 & .557 & .15 & 1.98 & $.049 *$ & .17 & 1.80 & .074 & .11 & 1.02 & .306 \\
\hline MASC under & -.14 & -1.43 & .154 & -.14 & -1.39 & .168 & -.01 & -.07 & .947 & -.09 & -.91 & .367 & .04 & .38 & .703 \\
\hline MASC no & -.16 & -1.48 & .142 & -.26 & -2.43 & $.016^{*}$ & -.05 & -.56 & .578 & .002 & .02 & .985 & -.12 & -.97 & .335 \\
\hline
\end{tabular}

$* p<.05, * * p<.01$

Abbreviations: MASC: Movie for the Assessment of Social Cognition, accurate $=$ accurate mentalization, hyper $=$ hypermentalization, under $=$ undermentalization and no $=$ no mentalization, $\mathrm{RFQ}-\mathrm{Y}$ :

Reflective function questionnaire for youth, U/C = Factor 1 uncertainty/confusion, I/C = Factor 2 Interest/Curiosity, Certitude = Factor3 Excessive certainty. 